\title{
Predicting NSAID related ulcers - assessment of clinical and pathological risk factors and importance of differences in NSAID
}

\author{
A S Taha, S Dahill, R D Sturrock, F D Lee, R I Russell
}

\begin{abstract}
Although ulcers are often associated with non-steroidal anti-inflammatory drugs (NSAIDs) little is known about the feasibility of predicting their development in patients taking NSAIDs. In addition, the ulcerogenic potentials of the newer NSAIDs, taken on long term basis, have not been compared with those of more established preparations. The aim of this study was to identify the clinical and pathological characteristics of patients at a higher risk of NSAID induced ulcers, measure the ulcerogenic potential of a variety of NSAIDs, and test the effect of these potentials on the predictability of ulceration. Altogether 190 long term NSAID users were studied. The presence of abdominal complaints, previous history of ulcers, arthritis related physical disability, anaemia, gastritis, and Helicobacter pylori status were all assessed as possible risk factors. NSAIDs were classified into established drugs (group I), and newer agents (group II). Group I included naproxen, indomethacin, diclofenac, ketoprofen, piroxicam, and flurbiprofen. Group II included fenbufen, nabumetone, ibuprofen, etodolac, azapropazone, and tiaprofenic acid. Of 63 ulcers identified in the study group, $51(81 \%)$ were seen in group I NSAID patients (51 of 132, 39\%) compared with 12 ulcers in group II (12 of $58,21 \%$ ), $p<0.02$; estimated relative risk (ERR): 2.41). In group I, 25 ulcers were found in 38 patients with abdominal pain (25 of 38, 66\%, p<0.01, ERR: 5.03); 18 in 25 $(72 \%)$ patients with a previous history of ulcers (p<0•001, ERR: 5•77), 26 in $44(59 \%)$ patients with debilitating arthritis $(p<0.001$, ERR 3.64), and 35 in $73(48 \%)$ patients with $H$ pylori associated gastritis $(p<0 \cdot 01$, ERR: $2 \cdot 48)$. The presence of these factors in group II patients did not influence the risk of ulceration. Group I NSAIDs were more likely to be associated with chemical gastritis and to intensify $H$ pylori related damage. Although silent ulcers are not uncommon in patients taking NSAIDs, recognition of the risk factors might help predict a significant number (up to $81 \%$ ), especially in those receiving group I NSAIDs.

(Gut 1994; 35: 891-895)
\end{abstract}

Over the years, several attempts have been made to predict the presence of peptic ulcers and various screening policies have been pro- posed to improve the yield of endoscopy. These included simple age restrictions ${ }^{12}$ and strategies to characterise patients at risk of benign or malignant ulcer disease. ${ }^{3-5}$ More recently it has been suggested that the detection of Helicobacter pylori by serology be used to diagnose peptic ulcers in dyspeptic patients without the need for endoscopy. ${ }^{6} 7$ Despite the increased frequency of ulcers in patients taking non-steroidal anti-inflammatory drugs (NSAIDs), very little is known about the risk factors for their development. Nor is it clear whether the above observations would apply to NSAID patients. This is because: (1) NSAIDinduced ulcers can be completely asymptomatic ${ }^{8}$; (2) the precise contribution of $H$ pylori to NSAID related peptic damage is not fully defined; (3) the specificity of some serological tests for $H$ pylori may be low in chronic NSAID users ${ }^{10}$; (4) there is a growing belief that the various NSAIDs may differ in their ulcerogenic potentials. ${ }^{11-13}$

This study aimed, therefore, to assess a group of clinical and pathological characteristics that might identify patients at a higher risk of having NSAID related ulcers and to test the possibility that such risk might vary according to the type of NSAID used.

\section{Patients and methods}

Patients aged 18 years or over were recruited from the rheumatology clinic provided they had osteoarthritis or adult rheumatoid arthritis. NSAIDs had to have been taken in therapeutic doses for at least four weeks. Patients were excluded if they had had gastric surgery, malignancy, or if they had taken anti-ulcer drugs or antibiotics within a week of endoscopy.

Blood was taken to measure the haemoglobin concentration, erythrocyte sedimentation rate (ESR), and $C$ reactive protein (CRP). Physical disability related to arthritis was measured using the Health Assessment Questionnaire. ${ }^{14}$ Patients who scored $2 \cdot 1$ or more were considered to have debilitating arthritis (finding much difficulty in performing their daily activities and needing to use several aids and devices). Informed consent was obtained and endoscopy was performed using midazolam for sedation. Gastric antral biopsy specimens were taken to test for $H$ pylori by both histology (two specimens) and culture (one specimen), as previously described. ${ }^{15}$ Gastritis was classified according to the Sydney system, ${ }^{16}$ which also encompasses chemical and lymphocytic gastritis. ${ }^{17-20}$

The following characteristics were assessed as possible risk factors: (1) upper abdominal 
TABLE I Characteristcs of patients taking established (group I) or newer (group II) NSAIDs

\begin{tabular}{lccc}
\hline & $\begin{array}{c}\text { Group I } \\
(n=132)\end{array}$ & $\begin{array}{l}\text { Group II } \\
(n=58)\end{array}$ & $\begin{array}{l}\text { All NSAID } \\
\text { patients } \\
(n=190)\end{array}$ \\
\hline Men & 32 & 23 & 55 \\
Women & 100 & 35 & 135 \\
Age (y) (median (IQ range)) & $56(46-60)$ & $54(46-66)$ & $55(46-62)$ \\
Smokers & 54 & 21 & 75 \\
Drinkers & 61 & 24 & 85 \\
Rheumatoid arthritis & 107 & 39 & 146 \\
Osteoarthritis & 25 & 13 & 38 \\
Duration of NSAID (y) (median & $2(1-4)$ & $1(1-3)$ & $2(1-4)$ \\
(IQ range)) & & & \\
\hline
\end{tabular}

TABLE II Duration of arthritis, its activity, and details of second line drugs

\begin{tabular}{lccc}
\hline & $\begin{array}{l}\text { Group I } \\
(n=132)\end{array}$ & $\begin{array}{l}\text { Group II } \\
(n=58)\end{array}$ & $\begin{array}{l}\text { All NSAID } \\
\text { patients } \\
(n=190)\end{array}$ \\
\hline $\begin{array}{l}\text { Duration of arthritis (y) (median } \\
(\text { IQ range) }\end{array}$ & $8(4-14)$ & $6(2-18)$ & $7(3-14)$ \\
ESR (mm/h) (median (IQ range)) & $24(9-47)$ & $22(10-42)$ & $23(9-44)$ \\
CRP (mg/) (median (IQ range)) & $13(8-30)$ & $11(9-29)$ & $12(8-29)$ \\
Second line drugs: & 31 & 5 & 36 \\
$\quad$ Gold & 31 & 15 & 46 \\
Sulphasalazine & 10 & 1 & 17 \\
Penicillamine & 13 & 4 & 17 \\
\hline Hydroxychloroquine & 13 & & \\
\hline
\end{tabular}

$\mathrm{ESR}=$ erythrocyte sedimentation rate, $\mathrm{CRP}=\mathrm{C}$ reactive protein.

symptoms, (2) previous history of ulcers, (3) debilitating arthritis, (4) anaemia (haemoglobin less than $11.00 \mathrm{~g} / \mathrm{dl}$ with iron deficiency picture), (5) gastritis, and (6) $H$ pylori status. NSAIDs were divided into two groups: group I (older or established agents) including naproxen, indomethacin, diclofenac, ketoprofen, piroxicam, and flurbiprofen and group II (newer agents) including fenbufen, nabumetone, ibuprofen, etodolac, azapropazone, and tiaprofenic acid. The ulcerogenecity of most of the newer preparations had been assessed previously in short term trials only..$^{12} 13$

Statistical analyses included the $\chi^{2}$ test, logistic regression, and the $95 \%$ confidence intervals for the estimated relative risk (odds ratio) where appropriate. The endoscopist and



Figure 1: The numbers of ulcers in the presence or absence of the various risk factors in group I NSAID patients. Apart from anaemia, all the factors significantly increased the risk of developing ulcers. ${ }^{*} p<0.02$ (compared with group II as a whole); ${ }^{\star} \star_{p}<0.001$;

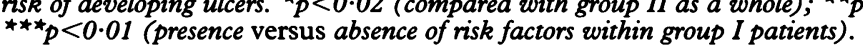

pathologists were not aware of patients' clinical details, and the study was approved by the local ethics committee.

\section{Results}

A total of 190 patients was studied. Their demographic characteristics are shown in Table I. Patients in both NSAID groups were similar in terms of sex distribution, age, smoking and drinking habits, type of arthritis, and the duration of NSAID intake. In addition, there were no significant differences between the two groups with regard to the duration of arthritis, its activity (as judged by the erythrocyte sedimentation rate and $\mathrm{C}$ reactive protein), and the types of second line drugs as shown in Table II.

The numbers of patients and ulcers in association with the various risk factors are illustrated in Figures 1 and 2. Patients taking group I NSAIDs had more ulcers than those receiving group II drugs. The presence of upper abdominal complaints, a previous history of ulcers, debilitating arthritis, or $H$ pylori significantly increased the risk of having ulcers in group I NSAID patients. These factors did not influence the risk of ulcers in group II patients, although more $H$ pylori positive patients than $H$ pylori negative patients had ulcers. It is worth noting that the ulcers described in this study were more common in the stomach $(n=36)$ than in the duodenum $(n=27)$. However, this pattern was reversed in smokers: 15 of 23 ulcers $(65 \%)$ in smokers were seen in the duodenum compared with eight $(35 \%)$ in the stomach $(p<0.05)$, and this did not differ in the two NSAID groups. Also, group I patients included 33 cases of anaemia ( 33 of $132,25 \%$ ) and 15 ulcers (15 of 33, 45\%) compared with seven of anaemia cases (seven of $58,12 \%, p<0.05$ ) and one ulcer (one of seven, 14\%, $\mathrm{p}<0.05$ ) in group II patients. In addition, 18 ulcers were found in 65 patients aged 60 years or over $(28 \%)$, regardless of the type of NSAID, and men and women were equally effected.

The estimated relative risk values and the $95 \%$ confidence intervals for the factors included in Figure 1 are presented in Table III. Patients with abdominal pain or a previous history of ulcers had the highest values, while those with anaemia had the lowest estimated relative risk. Using logistic regression, it was found that only the type of NSAID (group I versus group II), the presence of abdominal pain, and a previous history of ulcers were independent predictors of ulceration in the study group as a whole.

TABLE III The estimated relative risk (odds ratio (OR)) and $95 \%$ confidence intervals $(95 \% \mathrm{CI})$ for the individual risk factors for ulcer development in patients taking group I NSAIDs

\begin{tabular}{lll}
\hline Risk factors & (OR) & $(95 \% C I)$ \\
\hline Previous history of ulcers & $5 \cdot 77$ & $(2 \cdot 2,15)$ \\
Abdominal pain & $5 \cdot 03$ & $(2 \cdot 27,11 \cdot 2)$ \\
Debilitating arthritis & $3 \cdot 64$ & $(1 \cdot 7,7 \cdot 9)$ \\
Helicobacter pylori & $2 \cdot 48$ & $(1 \cdot 2,5 \cdot 12)$ \\
Group I NSAID as a whole & $2 \cdot 41$ & $(1 \cdot 17,4 \cdot 98)$ \\
$\quad$ (versus group II) & $1 \cdot 46$ & $(0 \cdot 7,3 \cdot 1)$ \\
Anaemia & &
\end{tabular}




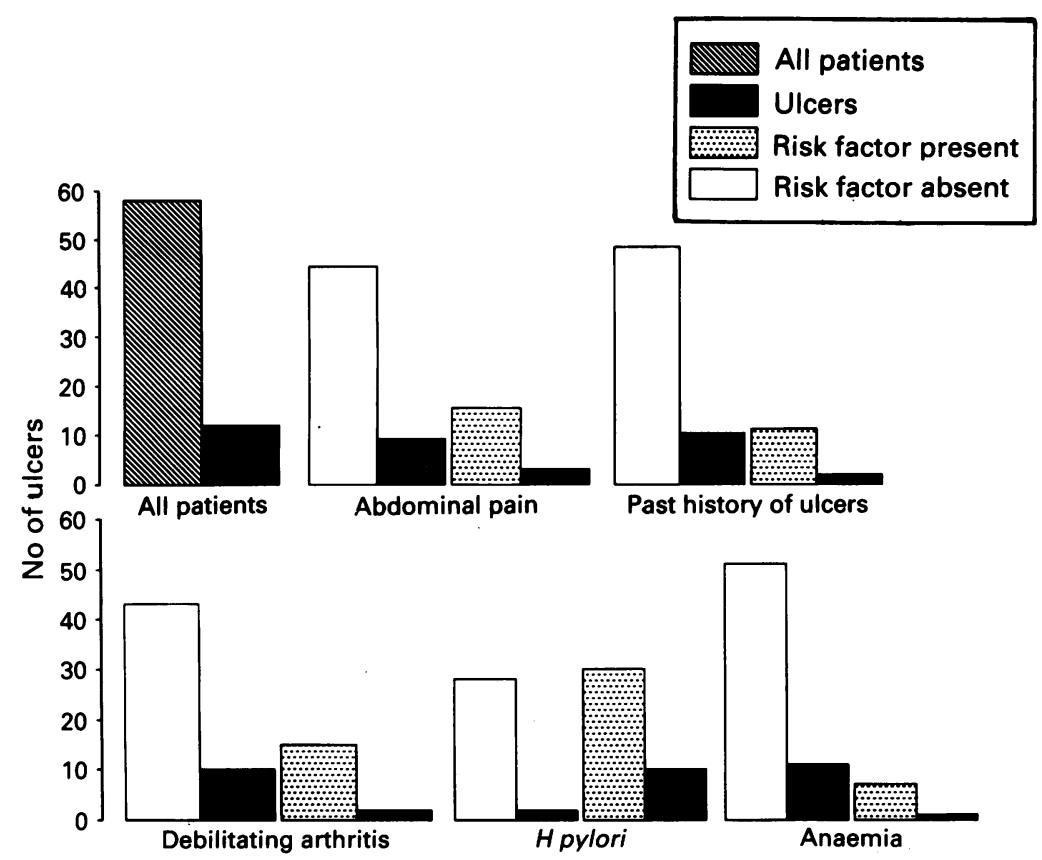

Figure 2: The numbers of ulcers in the presence or absence of the various risk factors in group II NSAID patients. The presence of $\mathrm{H}$ pylori tended to increase the risk of ulcer development but, like the other risk factors, no significant differences were found when group II NSAIDs were used.

TABLE IV Numbers of ulcers (\%) classified in relation to the presence or absence of upper abdominal pain

\begin{tabular}{llll}
\hline & \multicolumn{3}{l}{ Ulcers } \\
\cline { 2 - 4 } & \multicolumn{1}{l}{ Painful } & Painless \\
& $(\%)$ & $(\%)$ & Total \\
\hline Past history of ulcers $(\mathrm{n}=36)$ & $10(50)$ & $10(50)$ & 20 \\
Group I NSAID $(\mathrm{n}=132)$ & $23(45)$ & $28(55)$ & 51 \\
Group II NSAID $(\mathrm{n}=58)$ & $5(42)$ & $7(58)$ & 12 \\
Debilitating arthritis $(\mathrm{n}=59)$ & $12(40)$ & $18(60)$ & 30 \\
Anaemia (n=40) & $6(38)$ & $10(62)$ & 16 \\
Helicobacter pylori $(\mathrm{n}=103)$ & $25(56)$ & $20(44)$ & $45^{\star}$ \\
Gastric ulcers & $12(33)$ & $24(67)$ & 36 \\
Duodenal ulcers & $17(63)$ & $10(37)$ & 27 \\
\hline
\end{tabular}

* $H$ pylori was present in a total of 24 gastric and 21 duodenal ulcers, regardless of pain.

TABLE V Number of ulcers (\%) found per individual NSAID

\begin{tabular}{lllll}
\hline Group I $(n=132)$ & & & Group II $(n=58)$ \\
\cline { 5 - 5 } NSAID & Ulcers (\%) & & NSAID & Ulcers (\%) \\
\hline Naproxen $(\mathrm{n}=43)$ & $19(44)$ & & Fenbufen $(\mathrm{n}=18)$ & $4(22)$ \\
Indomethacin $(\mathrm{n}=28)$ & $12(43)$ & & Nabumetone $(\mathrm{n}=12)$ & $3(25)$ \\
Diclofenac $(\mathrm{n}=25)$ & $8(32)$ & & Ibuprofen $(\mathrm{n}=11)$ & $3(27)$ \\
Ketoprofen $(\mathrm{n}=15)$ & $4(27)$ & & Etodolac $(\mathrm{n}=5)$ & - \\
Piroxicam $(\mathrm{n}=12)$ & $5(42)$ & & Tiaprofenic acid $(\mathrm{n}=5)$ & $1(20)$ \\
Flurbiprofen $(\mathrm{n}=8)$ & $3(38)$ & & Azapropazone $(\mathrm{n}=5)$ & $1(20)$ \\
\hline
\end{tabular}

TABLE VI Gastric histological findings and peptic ulcers in the two study groups

\begin{tabular}{|c|c|c|c|c|}
\hline \multirow[b]{2}{*}{ Histological findings } & \multicolumn{2}{|c|}{ Group I $(n=132)$} & \multicolumn{2}{|c|}{ Group II $(n=58)$} \\
\hline & $\begin{array}{l}\text { Sample } \\
\text { size }\end{array}$ & Ulcers (\%) & $\begin{array}{l}\text { Sample } \\
\text { size }\end{array}$ & Ulcers (\%) \\
\hline $\begin{array}{l}\text { Chronic gastritis: } \\
\text { Active (type B) } \\
\text { Atrophic }\end{array}$ & $\begin{array}{r}70 \\
9\end{array}$ & $\begin{array}{c}31(44)^{\star} \\
4(44)\end{array}$ & $\begin{array}{r}32 \\
7\end{array}$ & $\begin{array}{l}6(19) \\
3(43)\end{array}$ \\
\hline $\begin{array}{l}\text { Special forms: } \\
\text { Reactive (chemical) } \\
\text { Lymphocytic } \\
\text { Normal }\end{array}$ & $\begin{array}{l}26^{\star} \\
6 \\
21\end{array}$ & $\begin{array}{r}14(54) \\
2(33) \\
-\quad\end{array}$ & $\begin{array}{r}5 \\
2 \\
12\end{array}$ & $\begin{array}{l}2(40) \\
1(50) \\
-\end{array}$ \\
\hline
\end{tabular}

${ }^{\star} \mathrm{p}<0.01$. Patients taking group I NSAIDs had more cases of chemical gastritis and $H$ pylori positive ulcers than group II patients.
The distribution of painful ulcers in patients with the various risk factors or characteristics is presented in Table IV. Most ulcers were painless, except in patients with $H$ pylori infection or duodenal ulceration, or both. Prediction of painless ulcers could, however, still be facilitated by identifying patients with a previous history of ulcers, debilitating arthritis, $\mathrm{H}$ pylori, or those receiving a group I NSAID.

The ulcerogenic potentials of the individual NSAIDs used in this study are shown in Table V. Naproxen, indomethacin, and diclofenac were the most commonly used agents, and like other drugs included in group I, their use was associated with the highest numbers of ulcers. Fewer ulcers were observed in users of group II NSAIDs as a whole, but because of the relatively small numbers of patients taking the individual agents in this group a direct comparison between them could not be made.

Table VI illustrates the numbers of ulcers classified according to the histological findings of the neighbouring gastric mucosa. $H$ pylori was isolated from all patients with ulcers and active (type B) or lymphocytic gastritis, and from none of the patients with normal histology or those with atrophic or chemical gastritis. Chemical gastritis was associated with high rate of ulceration, regardless of the type of NSAID, but group I NSAID patients had more cases of chemical gastritis. In addition, $H$ pylori positive active gastritis was more likely to be associated with ulceration in group I than in group II NSAIDs.

\section{Discussion}

This study shows that users of group I NSAIDs have more than twice the risk of developing ulcers than those using group II agents. In group I patients, ulcers were seen in $66 \%$ of those with upper abdominal pain, $72 \%$ with a previous history of ulcers, $59 \%$ with debilitating arthritis, and in $48 \%$ of patients with $H$ pylori related gastritis. These factors did not influence the risk of ulceration in group II patients. In addition, users of group I NSAIDs had more iron deficiency anaemia, chemical gastritis, and $H$ pylori positive ulceration. Logistic regression showed that only the type of NSAID (group I compared with group II), the presence of abdominal pain, and a history of ulcers were independent predictors of ulceration.

It has long been recognised that NSAID related peptic damage occurs in about $30 \%$ of NSAID users. $^{91421}$ It is not clear why NSAIDs cause ulcers in only a fraction of patients, the characteristics of whom remain poorly defined. Several suspected risk factors have been identified in epidemiological studies. These include female gender, ${ }^{22}$ old age, ${ }^{23} 24$ and a previous history of ulceration. ${ }^{25}$ The important data obtained from various epidemiological studies may be limited by the following factors. Firstly, these studies were intended to prove that serious ulcer complications occurred more commonly in NSAID users than in non-users, ${ }^{22} 24$ without identifying the specific differences, within the NSAID 
group, between those affected and those not affected by NSAIDs. Secondly, the role of the individual types of NSAID and the importance of the histological abnormalities have not been clarified. Thirdly, although the ultimate aim of studying ulcer disease relates to the prevention of serious complications, the natural history of ulcer formation is not necessarily identical to that of ulcer complications; there are often other indications for the immediate diagnosis of ulcers such as improving the quality of life by symptomatic relief and clarifying the causes of weight loss or dyspepsia. The above discussion might explain why, in our study, similar numbers of ulcers were observed in men and women, and in those aged 60 years or over compared with younger patients taking similar NSAIDs. The predominance of ulcer complications in elderly women has been attributed to the observation that most NSAID prescriptions are given to the elderly ${ }^{24}$ and to the fact that arthritic diseases are commoner in women.

One of the major difficulties faced in predicting NSAID induced ulcers relates to the painless nature of many of them. ${ }^{89}$ Indeed, 35 of $63(55 \%)$ ulcers diagnosed in this study were asymptomatic. The presence of upper abdominal complaints in NSAID users should not be ignored, however, as it was found to act as an independent predictor of ulceration in our study. On the other hand, the prediction of painless ulcers is made easier by identifying the risk factors assessed in this study.

Ulcers were found more frequently in patients with debilitating arthritis taking a group I NSAID than those with milder arthropathy taking a similar drug. The reason for this is not clear. One cannot exclude the possibility that NSAIDs were taken more regularly or in larger doses by the physically disabled patients, although there was no evidence of this in our study. Alternatively, the mucosal defences might have been weakened by the stress resulting from the debilitating disease, which in turn intensified NSAID related damage. ${ }^{1426}$

This study, like others, ${ }^{9}$ has shown that most ulcers in NSAID patients affect the gastric antrum. Duodenal ulcers, however, were twice as common as gastric ulcers in smokers and this is consistent with our recent finding suggesting that duodenal, but not gastric, mucosal blood flow is lowest in smokers taking NSAIDs. ${ }^{27}$

Group I NSAID patients included more cases of iron deficiency anaemia and peptic ulcers than group II subjects. In group I patients, peptic ulcers were not significantly more frequent in those with anaemia than in patients without this condition: the presence of anaemia was, therefore, a poor predictor of gastroduodenal ulceration. This might be explained by the fact that anaemia might be caused by lesions lower down the gastrointestinal tract or dietary factors, or both.

Many of the previous studies into the epidemiology or the pathogenesis of NSAID induced ulcers have assumed that all NSAIDs are equally damaging to the gastroduodenal mucosa. This contrasts with our findings, which are also supported by studies of short term $^{12} 13$ and chronic NSAID intake. ${ }^{11}$

The differences in the ulcerogenic potentials of the individual NSAID could be explained by their effects on mucosal prostaglandin synthesis, ${ }^{28}$ and by the gastric histological changes. The use of group I NSAIDs was associated with a greater number of cases of chemical gastritis known for its strong correlation with NSAID induced ulceration. ${ }^{18} 19$ Also, the presence of $H$ pylori seemed to intensify group I and not group II NSAID related damage. The inclusion of varying numbers of group II agents in some studies might account, at least partly, for their failure to show a synergistic effect between the NSAID and $H$ pylori infection causing endoscopic peptic damage. ${ }^{29} 30$ Although $H$ pylori was detected by standard methods (culture and histology) in our study, its use for screening for ulceration can be more easily achieved by methods such as the urea breath test or the appropriate serological tests that do not necessitate endoscopy.

In conclusion, the findings of this study might improve the yield of endoscopy and facilitate the prediction of painless ulcers in patients receiving NSAIDs. They also illustrate important differences between two groups of NSAIDs at the endoscopic and histological levels: the use of milder agents, where possible, is likely to reduce the risk of peptic ulceration. The above clinical and histological characteristics could also identify those who might benefit most from prophylactic anti-ulcer treatment.

We thank Miss Pamela Boothman for $H$ pylori culture, Dr Stephanie McLaughlin for help in the statistica analysis, and Mrs Ruth Simpson for her secretarial assistance. This study was partly funded by Merck, Sharp and Dohme, UK.

1 Williams B, Luckas M, Ellingham JHM, Dain A, Wicks ACB. Do young patients with dyspepsia need investigation? Lancet 1988; ii: 1349-51.

2 Hallissey MT, Allum WH, Jewkes AJ, Ellis DJ, Fielding JWL. Early detection of gastric cancer. $B M F$ 1990; 301: 513-15.

3 Mann J, Holdstock G, Harman M, Machin D, Lohry CA Scoring system to improve effectiveness of open access Scoring system to improve effectiventos

4 Davenport PM, Morgan AG, Darnborough A, De Dombal FT. Can preliminary screening of dyspeptic patients allow more effective use of investigational techniques? $B M F$ 1985; 290: 217-19.

5 Holdstock G, Harman M, Machin D, Patel C, Lloyd RS Prospective testing of a scoring system designed to improve case selection for upper gastrointestinal investigation. Gastroenterology 1986; 90: 1164-69.

6 Sobala GM, Crabtree JE, Pentith JA, Rathbone BJ Shallcross TM, Wyatt JI, et al. Screening dyspepsia by Shallos to Helicoter pylori. Lancet $1991 ; 338.94-6$.

7 serology to whe whether to diagnose Gastrointest Endosc 1991; 37: 577-9.

8 Skander MP, Ryan FP. Non-steroidal anti-inflammatory rugs and pain-free peptic ulceration in the elderly. $B M F$ 1988; 297: 833-4

9 Taha AS, Capell HA, Sturrock RD, Russell RI. Nonsteroidal peptic damage in theumatoid patients receiving second-line drugs. Am $\mathcal{F}$ Gastroenteral 1991; 86: 1588-91.

10 Taha AS, Reid J, Boothman P, Gemmell CG, Lee FD Sturrock RD, Russell RI. Serological diagnosis of Helicobacter pylori. Evaluation of four tests in the presence or absence of non-steroidal anti-inflammatory drugs. Gut 1993; 34: 461-5.

11 Shield MJ, Fenn GC, Kiff P, Stead H, Gies S. Do differential rates of NSAID-associated gastroduodenal damage exist? The results of a large cohort endoscopy study carried out in RA and OA patients. Br f Rheumatol 1990; 29 (suppl): 5 .

12 Taha AS, McLaughlin S, Sturrock RD, Russell RI. Evaluation of the efficacy and comparative effects on gastric and duodenal mucosa of pheumatol 1989; 28: 329-32. 
13 Lanza FL. A review of gastric ulcer and gastroduodenal injury in normal volunteers receiving aspirin and other non-steroidal anti-inflammatory drugs. Scand $\mathcal{f}$ Gastroenterol 1989; 24 (Suppl 163): 24-31.

14 Taha AS, Morran C, Sturrock RD, Russell RI. The Health Assessment Questionnaire as a predictor of non-steroidal peptic ulceration. Br $\mathcal{F}$ Rheumatol 1993; 32: 135-8.

15 Taha AS, Boothman P, Holland P, McKinley AW, Uphadyay R, Kelly RW, Russell RI. Gastric mucosa prostaglandin synthesis in the presence of Campylobacter pylori in patients with gastric ulcers and non-ulcer dyspepsia. Am ₹ Gastroenterol 1990; 85: 47-50.

16 Misiewicz JJ, Tytgat GNJ, Goodwin CS Price AB, Sipponen P, Strickland RG, et al. The Sydney system: a new classification of gastritis. In: Working Party Reports of the World cation of gastritis. In: Working Party Reports of the World Publications 1990: 1-10.

17 Dixon MF, O'Connor HJ, Axon ATR, King RFJG, Johnston D. Reflux gastritis: distinct histopathological entity. F Clin Pathol 1986; 39: 524-30.

18 Sobala GM, King RFG, Axon ATR, Dixon MF. Reflux gastritis in the intact stomach. $\mathcal{F}$ Clin Pathol 1990; 43: 303-6.

19 Taha AS, Nakshabendi I, Lee FD, Sturrock RD, Russell RI. Chemical gastritis and Helicobacter pylori - related gastritis in patients receiving non-steroidal anti-inflammatory drugs. Comparison and correlation with peptic ulceration. f Clin Pathol 1992; 45: 135-9.

20 Dixon MF, Wyatt J, Burk DA, Rathbone BJ. Lymphocytic gastritis - relationship to Campylobacter pylori infection. gastritis - relationship to Camp

21 Caruso I, Bianchi-Porro G. Gastroscopic evaluation of antiinflammatory agents. $B M \mathcal{F} 1980 ; 280: 75-8$.

22 Collier DSJ, Pain JA. Non-steroidal anti-inflammatory drugs and peptic ulcer perforation. Gut 1985; 26: 359-63
23 Armstrong CP, Blower AL. Non-steroidal anti-inflammatory drugs and life-threatening complications of peptic ulceration. Gut 1987; 28: 527-32.

24 Somerville K, Faulkner G, Langman M. Non-steroidal antiinflammatory drugs and bleeding peptic ulcer. Lancet 1986; i: 462-64.

25 Ehsanullah RSB, Page MC, Tidesley G, Wood JR Prevention of gastroduodenal damage induced by nonsteroidal anti-inflammatory drugs: controlled trial of ranitidine. $B M 71$ 1988; 297: 1017-21.

26 Silverstein F. Non steroidal anti-inflammatory drugs and peptic ulcer disease. An overview. Postgrad Med 1991; 89: 33-40.

27 Taha AS, Angerson W, Nakshabendi I, Beekman $\mathrm{H}_{\text {, }}$ Morran C, Sturrock RD, Russell RI. Gastric and duodenal mucosal blood flow in patients receiving nonsteroidal anti-inflammatory drugs - influence of age, smoking, ulceration and Helicobacter pylori. Aliment Pharmacol Therap 1993; 7: 41-5.

28 Taha AS, McLaughlin S, Holland PJ, Kelly RW, Sturrock RD, Russell RI. Effect on gastric and duodenal mucosal prostaglandins of repeated intake of therapeutic doses of naproxen and etodolac in rheumatoid arthritis. $A n n$ Rheum Dis 1990; 49: 354-8.

29 Graham DY, Lidsky MD, Cox AM, Evans DJ Jr, Evans DG, Alpert L, et al. Long-term non-steroidal anti-inflammatory drug use and Helicobacter pylori infection. Gastroenterology 1991; 100: 1653-7.

30 Loeb DS, Talley NJ, Ahlquist DA, Carpenter HA Zinsmeister AR. Long-term non-steroidal anti-inflammaZinsmeister AR. Long-term non-steroidal anti-inflammatory drug use and gastrointestinal injury: the role of
Helicobacter pylori. Gastroenterology 1992; 102: 1899-1905. 